\title{
Meconium Stained Liquor and Its maternal and Foetal Outcome
}

\author{
M. Sarmishta ${ }^{1}$, Usharani² \\ 1Department of Obstetrics and Gynaecology, Sri Ramachandra Medical University, Chennai, Tamilnadu, India. \\ 2 Department of Obstetrics and Gynaecology, Sri Ramachandra Medical University, Chennai, Tamilnadu, India.
}

\section{ABSTRACT}

\section{BACKGROUND}

Meconium stained Amniotic fluid is associated with higher rate of caesarean delivery, increased need for neonatal resuscitation and meconium aspiration syndrome. The risk factors for meconium stained amniotic fluid are both maternal and foetal. The maternal factors are hypertension, gestational diabetes mellitus, maternal chronic respiratory or cardiovascular diseases, post term pregnancy, preeclampsia and eclampsia. The foetal factors include oligohydramnios, intrauterine growth restriction and poor biophysical profile. We wanted to determine the maternal and foetal outcome and mode of delivery in patients with meconium stained liquor during labour.

\section{METHODS}

This retrospective study was conducted from January 2017 to March 2019 on patients admitted to labour ward in Sri Ramachandra Medical University. Out of 9600 deliveries over the period of 2 years, 110 patients who met the inclusion criteria were enrolled in the study.

\section{RESULTS}

The results of maternal and foetal outcome and mode of delivery were analyzed statistically. Increasing grade of meconium stained liquor is associated with increased adverse outcome. Association of meconium stained liquor with abnormal cardiotocography is associated with poor outcome, increased caesarean section rate and increased neonatal complications.

\section{CONCLUSIONS}

Meconium stained liquor alone is not associated with an adverse neonatal outcome. $90 \%$ of babies remained asymptomatic in spite of meconium stained liquor and required only routine care. Increasing grade of meconium stained liquor is associated with adverse maternal and foetal outcome. Association of meconium stained liquor with abnormal cardiotocography is associated with poor outcome, increased cesarean section rate, increased neonatal complications.

\section{KEY WORDS}

Apgar Score, Cardiotocography, Meconium Stained Liquor, Meconium Aspiration Syndrome
Corresponding Author:

Dr. M. Sarmishta,

Department of Obstetrics and Gynaecology,

Sri Ramachandra Medical University,

Chennai, Tamilnadu, India.

E-mail: sarmishta83@yahoo.co.in

DOI: $10.14260 /$ jemds/2019/790

Financial or Other Competing Interests: None.

How to Cite This Article:

Sarmishta M, Usharani. Meconium stained liquor and its maternal and foetal outcome. J. Evolution Med. Dent. Sci. 2019;8(49):3653-3656,

$10.14260 /$ jemds $/ 2019 / 790$

Submission 08-10-2019,

Peer Review 18-11-2019,

Acceptance 23-11-2019,

Published 09-12-2019. 


\section{BACKGROUND}

Meconium staining of the amniotic fluid has long been regarded as a sign of foetal distress. Although the exact cause is not known, meconium is thought to be passed from the foetal gastro-intestinal tract as a response to hypoxia, mesenteric vasoconstriction induced gut hyperperistalsis, falling umbilical venous saturation, vagal stimulation and normal physiological function of a mature foetus. Conflicting outcomes have been reported in the labours, complicated by meconium staining of the amniotic fluid, varying with the degree of meconium staining. Foetal distress is defined as alterations in the foetal heart rate (FHR) more commonly bradycardia and the passage of meconium in response to the underlying foetal hypoxia.

Variations in FHR, passage of the meconium in the amniotic fluid, pathological or abnormal cardiotocography and decreased foetal scalp blood $\mathrm{pH}$ are strong indicators of foetal distress. Meconium stained amniotic fluid is associated with higher rate of caesarean delivery, increased need for neonatal resuscitation and meconium aspiration syndrome. The risk factors for meconium stained amniotic fluid are both maternal and foetal. The maternal factors are hypertension, Gestational Diabetes mellitus, maternal chronic respiratory or cardiovascular diseases, post term pregnancy, preeclampsia, eclampsia. The foetal factors include oligohydramnios, intrauterine growth restriction, poor biophysical profile.

Aspiration of meconium by the foetus remains relatively common cause of perinatal morbidity and mortality. The foetus passes meconium into the amniotic fluid in $10 \%$ of all pregnancies, in $5 \%$ of these (1:200 of all pregnancies) the meconium is aspirated into the lungs of the foetus or the neonate. This can result in severe respiratory distress, meconium aspiration syndrome. Thick meconium by itself is not associated with adverse foetal outcome. However, the incidence of meconium aspiration syndrome increases in case of non-reassuring FHR and clinical condition of the newborn at birth.

The meconium aspiration syndrome can cause or contribute to neonatal death and in addition up to one-third of all cases in which aspiration occurs, develop long term respiratory compromise.

The meconium stained amniotic fluid is a clinical diagnosis with no practical confirmatory test. However, various methods have been tried to detect the presence of meconium in liquor and to prevent meconium aspiration syndrome. These methods include Amnioscopy during early labour and oropharyngeal suction and endotracheal intubation after birth. The perinatal morbidity and mortality associated with meconium aspiration syndrome can be brought down if the high risks are identified in the antenatal period and careful decisions are made about the timing and mode of delivery and vigilant monitoring of the labour.

This study was carried out to determine foetal outcome and mode of delivery in pregnant women with meconium stained liquor between 35-40 weeks after artificial rupture of membranes or spontaneous rupture of membranes.

\section{METHODS}

After obtaining ethical clearance, this retrospective study was conducted from January 2017 to March 2019. The study was done on patients admitted to labour ward, in the department of Obstetrics and Gynecology at Sri Ramachandra Medical University. Pregnant women with meconium stained liquor were included in the study. Out of 9600 deliveries over the period of 2 years, 110 patients had meconium stained liquor. All the patients in the study had undergone a standardized form of labour management. The patients who fulfilled the inclusion criteria were enrolled in the study. The data were gathered retrospectively. Patients detailed history, gestational age, per abdominal examination, per speculum and per vaginal examination, admission tests including intrapartum CTG were recorded in a predesigned proforma. The foetal heart rate tracing was classified as normal, suspicious, abnormal according the NICE (National Institute of Clinical Excellence) guidelines.[1] The meconium staining of the amniotic fluid was classified as Grade I, II, III. By visual examination after spontaneous or artificial rupture of membranes. Grade I meconium stained liquor is translucent, light yellow green in colour, grade II MSL is opalescent with deep green and light yellow in colour. Grade III is opaque and deep green in color. Delivery is expedited when foetal heart rate abnormalities were detected by safest mode of delivery either by instrumental vaginal delivery or caesarean section. All patients underwent full trial of labour and caesarian section was done only if trial of labour was unsuccessful or if there were obstetric indications including foetal distress. The APGAR score of neonates at 5 minutes, birth weight, NICU admission, and the neonates who had meconium aspiration syndrome and birth asphyxia were recorded.

\section{Inclusion and Exclusion Criteria}

The inclusion criteria are gestational age 35-40 weeks, cephalic presentation, singleton pregnancy or multiple pregnant patients with meconium stained liquor (grade I, II, III) after spontaneous or artificial rupture of membranes during labour. The exclusion criteria are those pregnant women with clear liquor after rupture of membranes or spontaneous rupture of membranes.

\section{Statistical Analysis}

The percentages of all the data were done and $p$ value by Chisquare test was done for the 3 grades of MSL and foetal outcome.

\section{RESULTS}

In this study the age distribution in whom meconium stained liquor is prevalent is seen. 40 patients between 20-25 years had meconium stained liquor (36.4\%). 47 patients had meconium stained liquor between the age group of 26-30 years ( $42.7 \%) .23$ patients between the age group of more than 30 years had meconium stained liquor (20.9\%). In this study the obstetrical score was studied, 89 Primis had meconium stained liquor (80.9\%) and 21 Multi's (19.1\%) of the meconium stained liquor. In this study shows term patients were $102(92.7 \%)$ and preterm 8 (7.3\%). In this 
study 4 patients had normal CTG (3.6\%), 50 patients had suspicious CTG (45.5\%), 56 patients had abnormal CTG (50.9\%). In this study shows 10 patients had Grade 1 MSL (9.1\%), 34 patients had Grade II MSL (30.9\%), and 66 patients had Grade III MSL (60\%).

\begin{tabular}{|c|c|c|c|}
\hline & & Count & $\mathbf{\%}$ \\
\hline \multirow{2}{*}{ Induction } & Induced & 47 & $42.7 \%$ \\
\cline { 2 - 4 } & Not Induced & 63 & $57.3 \%$ \\
\hline \multicolumn{2}{|r|}{ Table 1. Percentage of Patients Induced or Not Induced in } \\
Meconium Stained Liquor Patients \\
\hline
\end{tabular}

\begin{tabular}{|c|c|c|}
\hline Risk Factors & Count & $\mathbf{\%}$ \\
\hline Anaemia & 10 & $9.1 \%$ \\
\hline GDM & 21 & $19.1 \%$ \\
\hline GHT/PIH & 11 & $10.0 \%$ \\
\hline RH_NEG & 4 & $3.6 \%$ \\
\hline Preeclampsia & 2 & $1.8 \%$ \\
\hline Low Risk & 62 & $56.4 \%$ \\
\hline Table 2. Percentage of Risk Factors in Meconium \\
Stained Liquor Patients \\
\hline
\end{tabular}

\begin{tabular}{|c|c|c|c|}
\hline \multicolumn{2}{|c|}{ Outcomes } & Count & $\%$ \\
\hline \multirow{2}{*}{ Mode of Delivery } & Emergency LSCS & 108 & $98.2 \%$ \\
\hline & Assisted Vaginal & 2 & $1.8 \%$ \\
\hline $\begin{array}{r}\text { Table 3. Pe } \\
\text { Outco }\end{array}$ & $\begin{array}{l}\text { ge of Mode of D } \\
\text { Meconium Sta }\end{array}$ & $\begin{array}{l}\text { and th } \\
\text { uor } \mathrm{Pa}\end{array}$ & \\
\hline
\end{tabular}

\begin{tabular}{|c|c|c|c|}
\hline \multicolumn{2}{|c|}{} & Count & \% \\
\hline \multirow{2}{*}{ APGAR_1MIN } & $<7$ & 14 & $12.7 \%$ \\
\cline { 2 - 4 } & $>7$ & 96 & $87.3 \%$ \\
\hline \multirow{2}{*}{ APGAR_5MIN } & $<7$ & 3 & $2.7 \%$ \\
\cline { 2 - 4 } & $>7$ & 107 & $97.3 \%$ \\
\hline \multirow{2}{*}{ Birth Weight } & $<2.5 \mathrm{Kg}$ & 14 & $12.7 \%$ \\
\cline { 2 - 4 } & $>2.5 \mathrm{Kg}$ & 96 & $87.3 \%$ \\
\hline \multirow{2}{*}{ NICU } & Yes & 11 & $10 \%$ \\
\cline { 2 - 4 } & No & 99 & $90 \%$ \\
\hline \multicolumn{3}{|c|}{ Table 4. Foetal Outcomes in Meconium Stained Liquor- } \\
APGAR Score, Birth Weight, NICU Admission
\end{tabular}

\begin{tabular}{|c|c|c|c|c|c|c|c|c|}
\hline & \multicolumn{6}{|c|}{ Grade of MSL } & \multirow{3}{*}{$\begin{array}{c}p \\
\text { Value }\end{array}$} \\
\hline & & \multicolumn{2}{|c|}{ Grade I } & \multicolumn{2}{|c|}{ Grade II } & \multicolumn{2}{|c|}{ Grade III } & \\
\hline & & Count & $\%$ & Count & $\%$ & Count & $\%$ & \\
\hline \multirow{2}{*}{$\begin{array}{l}\text { APGAR } \\
1 \mathrm{~min} \\
\end{array}$} & $<7$ & 1 & $10.0 \%$ & 4 & $11.8 \%$ & 9 & $13.6 \%$ & \multirow{2}{*}{0.165} \\
\hline & $>7$ & 9 & $90.0 \%$ & 30 & $88.2 \%$ & 57 & $86.4 \%$ & \\
\hline \multirow{2}{*}{$\begin{array}{l}\text { APGAR } \\
5 \mathrm{~min}\end{array}$} & $<7$ & 0 & $0.0 \%$ & 1 & $2.9 \%$ & 2 & $3.0 \%$ & \multirow{2}{*}{0.338} \\
\hline & $>7$ & 10 & $100.0 \%$ & 33 & $97.1 \%$ & 64 & $97.0 \%$ & \\
\hline \multirow{2}{*}{$\begin{array}{l}\text { Birth } \\
\text { Weight }\end{array}$} & $<2.5 \mathrm{Kg}$ & 2 & $20.0 \%$ & 4 & $11.8 \%$ & 8 & $12.1 \%$ & \multirow{2}{*}{0.145} \\
\hline & $>2.5 \mathrm{Kg}$ & 8 & $80.0 \%$ & 30 & $88.2 \%$ & 58 & $87.9 \%$ & \\
\hline \multirow{3}{*}{ NICU } & Yes & 1 & $10.0 \%$ & 2 & $5.9 \%$ & 8 & $12.1 \%$ & \multirow{3}{*}{0.164} \\
\hline & No & 9 & $90.0 \%$ & 32 & $94.1 \%$ & 58 & $87.9 \%$ & \\
\hline & No & 9 & $90.0 \%$ & 32 & $94.1 \%$ & 58 & $87.9 \%$ & \\
\hline \multicolumn{9}{|c|}{$\begin{array}{c}\text { Table 5. Significant p Value and Percentage of the Grades of } \\
\text { Meconium and the Foetal Outcome }\end{array}$} \\
\hline
\end{tabular}

In this study Table 1: shows 47 patients were induced $(42.7 \%)$ and 63 not induced (57.3\%). In this study Table 2 shows risk factors - 10 patients were anaemic (9.1\%), 21 patients had GDM (19.1\%), 11 patients had PIH (10\%), 4 patients were Rh negative (3.6\%), and 2 patients had preeclampsia (1.8\%), the remaining 62 patients were low risk (56.4\%). In this study Table 3 shows 108 patients had Caesarean section (98.2\%) and 2 patients had Assisted vaginal delivery (1.8\%).

In this study Table 4 shows the foetal outcome with APGAR in $1 \mathrm{~min}<7-14$ babies (12.7\%), $>7-96$ babies (87.3\%). APGAR in 5 mins. $<7-3$ babies $(2.7 \%)$ and $>7107$ babies $(97.3 \%)$, Birth weight less than 2.5 Kgs. -14 babies (12.7\%), and more than 2.5 Kgs. - 96 babies (87.3\%). Babies that required NICU admission were 11 babies (10\%) and those who did not require were 99 babies (90\%).

In this study Table 5 shows foetal outcome according to the grades of meconium stained liquor. In all the three grades the APGAR in $1 \mathrm{~min}$, APGAR in 5 mins, Birth weight and NICU admissions -p value is not significant.

\section{DISCUSSION}

In this study the age distribution in whom meconium stained liquor is prevalent is seen. 40 patients between $20-25$ years had meconium stained liquor (36.4\%). 47 patients had meconium stained liquor between the age group of 26-30 years $(42.7 \%) .23$ patients between the age group of more than 30 years had meconium stained liquor (20.9\%).

In this study the obstetrical score was studied, 89 Primis had meconium stained liquor (80.9\%) and 11 Multi's (19.1\%) of the meconium stained liquor. In this study shows term patients were $102(92.7 \%)$ and preterm 8 (7.3\%). In this study shows 47 patients were induced $(42.7 \%)$ and 63 not induced (57.3\%). In this study CTG patterns 4 (3.6\%) patients have normal patterns and 106 (96.4\%) patients have abnormal patterns whereas in Meena et al[2] study $110(44 \%)$ of patients had normal pattern and $140(56 \%)$ patients had abnormal pattern. In Nirmala et al[3] study 63 (4.97\%) patients had normal patterns and 1204(95\%) had abnormal patterns.

In this study shows risk factors between various studies the risk factors were Anemia $10(9.1 \%)$ patients, gestational diabetes 21(19.1\%), gestational hypertension 1 (11.8\%), Rh negative $4(3.6 \%)$ patients. In Meena et al ${ }^{[2]}$ study risk factors were gestational diabetes $8(3.2 \%)$, gestational hypertension 12 (4.8\%), Rh negative 12 (4.8\%), 3 (1.2\%), oligohydramnios 9 (3.6\%), heart disease $5(2 \%)$, respiratory disease $3(1.2 \%)$, IUGR 8 (3.2\%), PROM 9 (3.6\%), higher maternal age 5(2\%), teenage pregnancy $3(1.2 \%)$, postdatism 82 (32.8\%). In Shankyan et al[ ${ }^{4]}$ risk factors are gestational hypertension 17(10.6\%), IUGR- 21 (13.2\%), PROM-20 (12.5\%), higher maternal age $19(11.9 \%)$, postdatism 47 (29.5\%).

In this study shows the total number of deliveries is 9600 out of which MSL is 110 (1.14\%). Grade I MSL is 10 (9.1\%), Grade II MSL is $34(30.9 \%)$ and Grade III MSL is $66(60 \%)$. In Nirmala et al[3] total number of deliveries is 1267 out of which MSL is 100 (7.89\%), Grade I MSL is 39\%, Grade II MSL is $43 \%$, Grade III MSL is $18 \%$. In Surekha et al[5] study total number of deliveries is 3673 out of which MSL is 120 (3.48\%). Grade I MSL is $34.16 \%$, Grade II MSL is $29.16 \%$, Grade III MSL is $36.66 \%$.

In this study shows the mode of delivery- Caesarian section 108 (98.2\%), Instrumental 2 (1.8\%). In Meena et al[2] Caesarian 106 (42.4\%), Normal 86 (34.4\%), Instrumental 58 (23.2\%). In Patil et al[6] Caesarian is $42 \%$, In Espinheira MC et al[7] Caesarian $62.5 \%$. In this study shows the foetal outcome - APGAR in $1 \mathrm{~min}$ is <7-14 (12.7) and >7-96 (87.3\%), APGAR in 5 mins $<7-3$ (2.7\%), > -107 (97.3\%), Birth weight $<2.5 \mathrm{Kgs}$ is $14(12.7 \%)$ and $>2.5 \mathrm{Kgs}$ is $96(87.3 \%)$, Birth Asphyxia $11(10 \%)$, NICU admissions needed is $4(3.6 \%)$ and not needed 106 (96.4\%).

In Meena et al[2] APGAR in 5 mins $<7-82$ (32.8\%), Birth weight $<2.5 \mathrm{Kgs}$ is $52(20.8 \%)$ and $>2.5 \mathrm{Kgs}$ is $198(79.2 \%)$, Birth Asphyxia is 5 (14.28\%), Meconium aspiration syndrome is $14(40 \%)$, NICU admissions needed is $35(14 \%)$. In Nirmala et al[4] APGAR in 5 mins $<7-1(0.18 \%)$, Birth weight $<2.5 \mathrm{Kgs}$ is 2 (11.11\%). In Rekha Kumari et al[7] Birth asphyxia is 1 
(1.3\%), NICU admissions not needed is 63 (84\%). In Espinheira MC et al[8] Meconium aspiration syndrome is $5 \%$, NICU admissions is $1.4 \%$.

\section{CONCLUSIONS}

Meconium stained liquor alone is not associated with an adverse neonatal outcome. $90 \%$ of the babies remained asymptomatic in spite of MSL and required only routine care. Increasing grade of MSL is associated with adverse maternal and foetal outcome. Association of MSL with abnormal CTG is associated with poor outcome, increased cesarean section rate and increased neonatal complications.

\section{REFERENCES}

[1] National Collaborating Centre for Women's and Children's Health. Intrapartum care: care of healthy women and their babies during childbirth. NICE Clinical Guideline 55. London: National Institute for Health and Clinical Excellence, 2007.
[2] Meena PV, Seetha P. Meconium stained liquor and its foetal outcome - retrospective study. IOSR Journal of Dental and Medical Science 2013;6(2):27-31.

[3] Nirmala D, Anshu P, Urmila D, et al. Meconium staining of amniotic fluid, a poor indicator foetal compromise. JK Science 2010;12(4):184-6.

[4] Shankyan N, Sharma VK, Sarin R, et al. Predictors of meconium stained amniotic fluid: a possible strategy to reduce neonatal morbidity and mortality. J Obstet \& Gynaecol India 2006;56(6):514-7.

[5] Surekha T. The significance of meconium stained amniotic fluid - a cross sectional study in rural set up. Int J Biomed Adv Res 2012;3(12):861-6.

[6] Patil KP, Swamy MK, Samatha K, et al. A one year cross sectional study of management practices of MSAF \& perinatal outcome. J Obstet Gynecol India 2006;56(2):128-30.

[7] Kumari R, Srichand P, Devrajani BR, et al. Foetal outcome in patients with meconium stained liquor. J Pak Med Assoc 2012;62(5):474-6.

[8] Espinheira MC, Grilo M, Rocha G, et al. Meconium aspiration syndrome - the experience of a tertiary center. Rev Portal Pneumol 2011;17(2):71-6. 